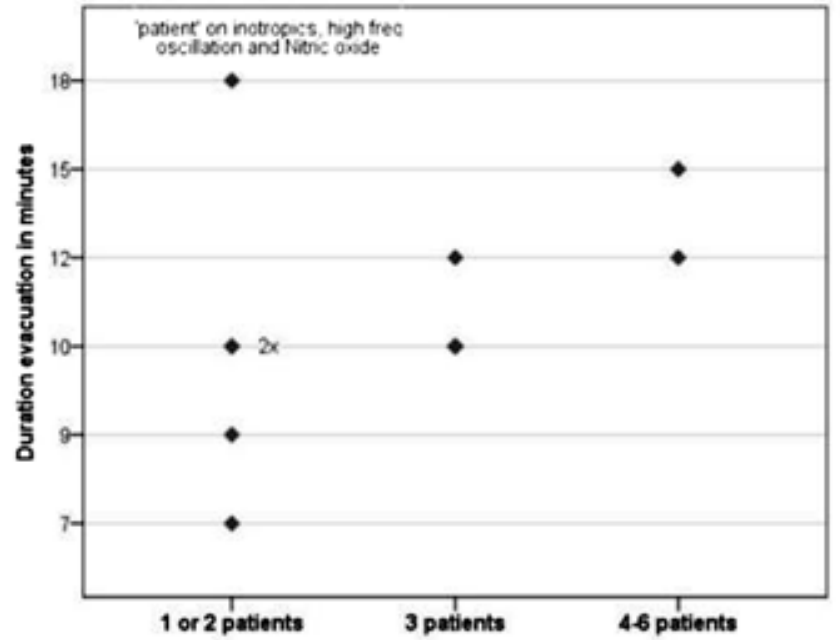

Abstract 1887 Figure 1

Conclusions The workgroup felt it necessary to improve the drills by using colored vests to single out participants in the drill, wearing goggles mimicking poor visibility, and a flowchart demonstrating stepwise evacuation. Participants felt it was useful to practice evacuations.

\section{EXPECTED OUTCOMES AS FACILATATORS IN EVALUATING SOLUTION OF NURSING DIAGNOSIS "ANXIETY"}

doi:10.1136/archdischild-2012-302724.1888

${ }^{1} \mathrm{M}$ Uzun, ${ }^{2} \mathrm{G}$ Cimete. ${ }^{1}$ Pediatric Nursing, Bulent Ecevit University Zonguldak School of Health, Zonguldak; ${ }^{2}$ Pediatric Nursing, Maltepe University School of Nursing, Istanbul, Turkey

Aim Research was performed as descriptive. It was indented to determine the effect of expected outcomes on decision making through the solution of "anxiety" as a nursing diagnosis.

Method The sample were composed from 50 mothers of child with cancer. Data were collected with Care Giver Assesment Form. "Anxiety" were determined as a nursing diagnosis for mothers. 5 NIC activity group were used for solution of diagnosis. 9 expected outcomes were determined for the evaluation of solution. All outomes were evaluated in stages of "How many times did they target", "Did we have expected results?" and "Did we solve the problem?" At the end of evaluation we can say "The problem solved" or "It is still going on."

Results 37 of 50 mothers had anxiety. Expected outcomes were "recognize own anxiety and express coping methods, use effective coping methods, express positively about reducing stress, express activites on face and body as signs of reducing stress, express increase concreation and reliability in thinking, express increase in problem solving process, express increase in self confident, increase for envorimental interest, decrease in pulse and blood pressure through normal values". The problem were solved in different time interval in different mothers by the help of outcomes. All outcomes targeted once for 37 mothers. We couldn't reach the targets for five mothers so "anxiety" were solved for 32 of mothers completely.

Conclusion Expected outcomes facilitate the decision making about solution of nursing diagnosis effectively.

\section{9 \\ HAND HYGIENE ADHERENCE AMONG HEALTH CARE WORKERS IN CAIRO, EGYPT}

doi:10.1136/archdischild-2012-302724.1889

T Rashdan. Medical University of South Carolina, Charleston, SC, USA
The purpose of this process improvement project was to help guide a medical center in a low income country, Egypt, to reduce the incidence of healthcare associated infections by improving hand hygiene practice among its healthcare workers. The goal was to increase hand hygiene by utilizing a strategic educational plan for HCWs using the WHO's guidelines of "5 Moments of Hand Hygiene" (WHO, 2009).

The project was conducted to increase compliance in healthcare workers' hand hygiene in an intensive care unit. The pre-observation audit identified that $42 \%$ of physicians and $71 \%$ of nurses performed hand hygiene - Moment 1 - before touching a patient. The post observation audit identified that $53 \%$ of physicians and $83 \%$ of nurses performed hand hygiene - Moment 1-before touching a patient. Nurses were observed performing 193 opportunities of hand hygiene during Moments 1-5. In all areas, nurses maintained or improved their hand hygiene practices following the World Health Organization's "5 Moments of Hand Hygiene." Subsequently, the one-on-one education, Moment 2 - before clean/aseptic procedure practice improved from $0 \%$ to $100 \%$ adherence. One-onone education on hand hygiene using "5 Moments of Hand Hygiene" among healthcare workers in an intensive care unit proved to be a successful strategy for improving hand hygiene compliance.

\section{CHILDREN, THE FUTURE OF NURSING. A STUDY ABOUT CHILDREN'S PERCEPTIONS OF NURSES' ROLE}

doi:10.1136/archdischild-2012-302724.1890

${ }^{1} \mathrm{~F}$ Festini, ${ }^{2} \mathrm{C}$ Tonfoni, ${ }^{2} \mathrm{~F}$ Giusti, ${ }^{1} \mathrm{~S}$ Bisogni. Italian Society of Pediatric Nursing Science SISIP, Pistoia; ' University of Florence, Florence, Italy

Background Nursing shortage is a major problem. Strategies have been adopted to contrast it. One is to increase the appeal of nursing profession to young people, to increase the number of new nurses entering the profession. No intervention has considered children in primary school -the period of life when children start fantasizing about what to do when they grow up- as possible target of an information campaign about Nursing.

Goal To investigate what perception children have of Nurses and their propensity to become a Nurse when they grow up.

Methods Cross-sectional study. Primary school 5 thgraders (age 10) were asked to answer a 6-item questionnaire and to draw a Nurse.

Results 245 questionnaires and drawings were collected. $60 \%$ of children consider the Nurse as the one who "takes care" or "helps" sick people, while 23\% say Nurse "helps the doctor". $28 \%$ drew a Nurse with a syringe. Only $8 \%$ represented a Nurse talking with patient. Many of the drawings representations seem influenced by stereotypes: red cross on the uniform (61\%), female nurses with starched white hat, skirt and heels (25\%). $17 \%$ of children state they want to be a Nurse when they grow up; of them $63 \%$ are girls.

Discussion The majority of children have a correct idea of Nurses' role, although their image is influenced by stereotypes. Unexpectedly, $1 / 6$ children think of becoming a Nurse. An educational campaign about Nursing directed to primary schooler may correct wrong stereotypes about Nurses and encourage children interested to nursing to cultivate their dream.

\section{DISEASE COURSE AND SELF-REPORTED DAILY LIFE EXPERIENCES OF YOUNG ADULTS WITH JUVENILE IDIOPATHIC ARTHRITIS THROUGH ADOLESCENCE}

doi:10.1136/archdischild-2012-302724.1891

1/ Östlie, ${ }^{2,3}$ J Johansson, ${ }^{4} \mathrm{~A}$ Aasland, ${ }^{5,6} \mathrm{~A}$ Möller. 'Department of Nursing; ${ }^{2}$ Gjövik University College, Gjøvik, Norway; ${ }^{3}$ Karlstad University, Karlstad, Sweden; ${ }^{4}$ Section of Psychosomatics and CL-Child Psychiatry, Department of Clinical Neurosciences for 